\title{
New Learning, New Teaching, New Entrepreneurship, New Eco-sphere
}

\author{
Ji Shaoyou \\ President \\ Chaoshan College, China \\ Email: 1109608751@qq.com
}

As it is known, China is a country with a long history, and in this Internet Age, changes are taking place in China at high speed. The new leadership of China is faced with a series of complex challenges. In September 2013, Chinese President Xi Jinping proposed a Silk Road Economic Belt and in October a $21^{\text {st }}$-Century Maritime Silk Road; together now referred to as the Belt and Road Initiative. The Initiative aims at building a community of shared interests, responsibility and destiny with mutual political trust, economic integration and cultural inclusiveness. Investments and trade cooperations are major tasks in building the Belt and Road. As a member of higher education community, how could we be of any assistance in solving the employment problem for the government, upgrade the traditional foreign trade for the enterprises and train innovative students for the society? Consequently, I select the theme Disruptive Innovation: Shifting the way of learning. And the title of my sharing is "New Learning, New Teaching, New Entrepreneurship \& New Eco-sphere".

\section{Brief Introduction of Chaoshan College}

Chaoshan College (CSC for short) is well-known for its entrepreneurship education in China, especially in the field of cross-border E-commerce. Our college students are running shops on various platforms such as Amazon, Wish, AliExpress and Dunhuang Gate etc. Their sales revenues are satisfactory and their business has spread to more than 100 countries and regions all over the world. Based on the achievements that we have made, I will share with you our future academic project, namely, to build a joint cross-border business school among Asian universities. It consists of 4 parts as follows.

\section{Part 1, New Learning}

An online education platform called "Hi Seller" is under construction, where method in opening an E-shop quickly, practice in operating the business efficiently, knowledge of cross-border logistics and tool analysis outside the E-shop can be conveniently acquired from this new way of learning. Platforms such as amazon, Shopee, Lazada, e-bay, Ali-Express are all among the range of choices for the students. "Hi Seller" has multilingual versions, including English, Chinese, Indonesian, Malay, etc. More and more new versions like Russian, Spanish, German, Vietnamese, Korean, Japanese and so on will also be launched gradually. Students are free to interact with the lecturers online and they only need to spend seven days to finish the learning of some platform courseware. This means that within a month the study of practical courseware can be done from four mainstream cross-border E-commerce platforms. For the website itself, the information will be updated twice a month and all of the 
demonstrations are recorded from real life.

Quantities of skills can be developed for the students:

$1^{\text {st }}$, through operating cross-border e-commerce platforms, they achieve a mode of thinking on how to run a global business.

$2^{\text {nd }}$, they will be familiar with the basic knowledge to operate different platforms' accounts.

$3^{\text {rd }}$, they will learn how to do market research and cost control, how to deal with warehousing and pricing etc.

$4^{\text {th }}$, they will be well aware of some useful skills to handle orders, customer services and promotion within some platforms.

$5^{\text {th }}$, they will comprehend the concepts and processes of cross-border e-commerce logistics and put them into practice.

$6^{\text {th }}$, they will understand the Value Added Tax (VAT) in various countries and pay attention to different requirements.

\section{Part 2, New Teaching}

Against the background of cross-border e-commerce, requirements from students are changing, theory of teaching must be put into practice and especially for students who want to start a business. Guidance in funding and product sources shall be available, also some actual needs such as oversea laws, tax, logistics and warehousing services are required.

Right now we are trying some innovative teaching models. Some typical workshops that are running in CSC Guangzhou Incubation Center, including some basics of teaching workshop, back-end operation workshop, product video workshop, art design workshop and customer service workshop are all popular with many students. The characteristics of the new teaching are reflected in two sections. Firstly the teachers share their knowledge, which are made up of online and offline resources. Online resources include live online classes simulating the real ones, supporting sorts of players with multilingual versions, sharing of teaching courseware such as presentation slides, audio and video resources, cross-border interactions by which online question and answer (Q\&A) within 24 hours can be realized to facilitate communications among the students and a collaborative atmosphere could be formed as well. Offline resources include regional incubation center building, by using CSC Guangzhou Branch as a template to build activity centers for teachers interactions in different colleges and universities against market rules changes in cross-border e-commerce. Newest operation skills and techniques sharing will be uploaded and offered regularly from CSC to students and teachers of other colleges and universities. Plate construction by teachers together with students to establish practice teams according to different e-commerce platforms, enhancing the realization progress of cross-border e-commerce. 
Secondly, there are four steps for students to keep pace with teachers:

Step One, students learn the latest teaching courseware from the Joint Cross-border Business School by PC.

Step Two, teachers guide the students to practice around the clock by using mobile phone.

Step Three, through resource sharing by various colleges and universities, basic learning of some cross-border e-commerce can be completed within seven days.

Step Four, knowledge and profit can be both achieved in the end.

\section{Part 3, New Entrepreneurship}

There are lots of outstanding students who run their own e-shops successfully inside the college instead of outside the college. However, there are four road blocks in front of us, including the lack of funding to hire staff or rent an office space, no practical methods to learn and no overseas warehouse to coordinate with. Then how to solve the above problems? "Hi Seller" is undoubtedly an appropriate platform for students to start their business in the campus. Multilingual versions choice, data packages offer, 24-hour online service, various platforms operation make individual or team entrepreneurship possible. Distribution of goods in stock, one-click for data input and overseas warehousing services are all available here at "Hi Seller". Zero stock, zero team members, no need to employ art designer, support staff or warehouse keeper, zero after-sale service and zero risk characterize "Hi Seller".

\section{Part 4, New Eco-sphere}

Combined with the issue of employment, besides the traditional occupational mode, there are more options for students both at home and abroad, including operational employment and innovative self-employment in cross-border e-commerce. Meanwhile a brand new generation of teachers emerges. Besides the original members of teachers, there are also teachers from cross-border e-commerce enterprises, teachers guiding students' entrepreneurship and teachers who are e-sellers themselves. Finally, an online Eco-sphere will come into being. Overseas warehousing, overseas distribution of goods in stock, international express shipments, global trademark registrations, foreign product packing and external goods return services are all the services that can be offered. One major characteristic is the overseas warehousing system, where every college or university served as an independent overseas location. Besides, more functions are required for the overseas incubation centers, which shall be entrepreneurship hubs offering practice opportunities and new platform to deliver talented people by goods in stock display, teaching courses adjustment and all-time responsible teaching team training.

\section{Conclusion}

In this disruptive era, missions fall on the shoulders of the high education sector to change the world. Ways of learning shall be shifted from teacher-centered to student-centered. Lecturers become mentors by using various teaching tools and means. Innovative technologies shall be applied to cultivate students' self-learning 
ISSN : :2662-5514

e-ISSN : :2654-6981

DOI : 10.9744/ahec.1.1.23-26

and working abilities. At last, organic combination of new learning, new teaching and new entrepreneurship can be realized as a new Eco-sphere. 